\title{
Literature in the Teaching of English as a Foreign Language
}

\author{
Jenny Elliott de Riverol \\ The British Council, Valencia
}

\begin{abstract}
This paper secks to examine the place of literature in the foreign language class and looks at the enrichening effect its use has, both from a cultural and linguistic viewpoint. Examples given will be mainly from personal experience gained from teaching adult Spanish speakers.
\end{abstract}

It would appear that over the last few years there is a positive swing back to using literature in a language context, or at least literary texts are being used hand in hand with other authentic material and with this use, opening up a whole new world to the language learner. Previously, literary texts were thought to embody archaic language which had no place in the world of audiolingualism where linguists believed in the primacy of speech, thus considering the written form somewhat static. Later, the emergence of the Communicative Approach meant that literature could be used as a stimulus for discussion and genuine communication, rather than the learners being required to simply repeat set phrases. Likewise, using literature could also be considered to be a means of internalising specific grammatical constructions and reinforcing points previously learned. Enkvist claims that a study of a variety of texts «will provide a short-cut to the extensive experience of linguistic items in context that native speakers acquire by direct exposure» (Enkvist, Spencer and Gregory 5). Some language teachers might still feel reluctant to use literature, perhaps because of certain cultural implications. Possible reasons for this will be raised later when this paper discusses what teachers might like to take into consideration when choosing texts for classroom use.

In fact, one of the advantages of using literature is that it can «serve as a medium to transmit the culture of the people who speak the language in which it is written» (Valdes 137). Valdes also warns us however, not to use literature only as a means of imparting cultural information (Valdes 137).

Before this paper goes on to look at specific classroom activities we should perhaps clarify what we mean by literature. Moody (Brumfit 19) claims that it is constructions which can be oral or written and are designed for human communicative needs. It would seem that all languages and cultures have some form of literature. Brumfit states 
that any work of literature «is a language act which exploits the resources of the time and place in which is it written» (Brumfit Language and Literature Teaching 116). This appears to be a widely accepted definition in that literature is somehow enduring and not ephemeral. However, its meaning does not remain static since «a literary work can transcend both time and culture to speak directly to a reader in another country or a different period of history» (Collie and Slater 3). Literature then provides us with authentic language-works which have not been written specifically with the foreign learner in mind. Recent course materials incorporate examples of authentic language in the text book, such as cartoons, advertisements, tickets, timetables and so on. Thus, literature provides the learner with another example of such authentic material.

The language teacher will probably encourage the learner to read widely anyway, beginning perhaps with simplified readers and going on to light fiction and then more complex works. The line between the latter and literature may not be easy to define. Indeed some linguists claim that there is no such thing as literary language (Brumfit and Carter 6) but rather, that language may be used in a literary way even though they might not agree with the term 'literary language.' We are reminded by Hill that texts chosen for use need not necessarily be «Great Literature» (Hill 15). We should also be aware that even though literature may be a rich source of linguistic variety, the teacher should not turn each text into a series of language exercises since we would not wish to mar the learner's enjoyment.

Choosing a text to be used in the classroom should be carefully considered. One of the objections to using literary texts which we have already observed has been that they might enbody language which is not typical of everyday life, nor might it be like the language encountered in modern textbooks. Linguistic and stylistic appropriacy does, of course, have to be considered. The teacher might also take into account the needs and abilities of the learner group, and also analyse the amount of background information required for a true appreciation of the text. An appropriate choice of text will provide the learners with examples of many features of the written language-the structure of sentences, the variety of form, the different ways of connecting ideas. This will enrich their own writing skills.A literary text might also provide the stimulus for oral work and encourage students to be aware of the vast range of language which is incorporated in a particular text. Likewise, the need to use the imagination when discussing literature «enables the learners to shift their attention beyond the more mechanical aspects of the foreign language system» (Collie and Slater 5). The learner may find himself completely absorbed by the work and this will lead to a high motivation level making the activity memorable and enjoyable.

When considering the abilities of the learners perhaps we should establish that a language minimum is desirable, both to be able to respond personally in the second language and to recognize particular aspects of language use. However, with beginner groups one might use limericks in order to practise particular sounds. The learners are given copies of the limerick with the final word in each line missing. The missing words are mixed up at the bottom of the page and the phoneme sign is written where the missing words should be placed. In groups the learners practise saying the words and write them in the spaces. This is merely a pronunciation exercise; the learners are not required to be able to understand the piece as a whole: 
There was a faith healer of ...../di:l/

Who said, «Although pain isn't ..... /ri:l/

If I sit on a ..... /pin/

And it punctures my ..... /skin/

I dislike what I fancy I ...... /fi: I/ (from Poem into Poem, author unknown)

(Deal, real, pin, skin and feel are the missing words)

In the above exercise the learners will be communicating in the mother tongue even though the missing words will be said in the target language. However, the activity is usually fun and therefore motivating.

Cultural implications should also be considered when planning teaching materials which involve literature. Shared history, religion or literary tradition make cross referencing easier. Similarly, literary convention will also enable cultural cross reference, for example the sonnet is a common format in most of Europe. Prose extracts, short stories or poems might be suitable for use in the language classroom simply because of the limitation of time available. Poetry has an immediate appeal since it has universality with common themes, albeit their treatment being different. The conventions governing the language of poetry are likewise familiar; rhythm, rhyme, metre and the like.

When choosing literary texts for use with Spanish adults, I have therefore considered the above points. I have tended to choose works which also might be read in Spanish translation or which perhaps have been made into films and shown in cinemas in Spain. A recent theatre production of Alice in Wonderland, which is also familiar in Spanish culture, prompted me to use an extract from the work in class. The Jabberwocky, from the same work, is usually found to be highly amusing and original and requires the learners to discuss which words exist and which ones are nonsense words. The teacher might ask the learners to rewrite some of the passage, using modern prose:

'Twas brillig and the slithy toves

Did gyre and gimble in the wabe;

All mimsy were the borogroves,

And the mome raths outgrabe. (Lewis Carroll)

This type of activity is quite a complete one since the learners are using several skills and discussion should be done in the target language since this particular task will be suitable for advanced learners. Alternatively, the teacher might give out short prose extracts from different sources, followed by phrases said by some of the characters who appear in the extracts. In groups the learners have to discuss who they think said which phrase. A follow up activity might be to ask further questions in order to clarify certain aspects of character, which the passages illustrate, for example:

Who would lend you some money?

Who spends a lot on his appearance? 
This kind of activity requires quite a lot of imagination but the teacher will have considered this when choosing such an activity with a particular group. As far as language function is concerned, the learners will be agreeing with each other, disagreeing, giving opinion and making suppositions. They also might be able to identify with some of the characters and this could give rise to some interesting discussion work. Alternatively, the learners might be asked to guess the title of a prose extract or some poetry. Another worthwhile activity with advanced learners is to rewrite some poems without punctuation and mix them up with prose extracts. The learners have to identify which extracts were originally written in the form of poetry. This leads to much discussion and it is surprising to see how even experienced learners will make erroneous choices. Jigsaw listening or reading tasks are another way of using literary texts. The learners are given the lines of a poem in the incorrect order. The activity is more fun if the lines are written on large strips of card. In groups learners read out loud the line they have and the group decides what they think the correct order is. The teacher might say what the opening line is. As a listening activity, the teacher reads out the poem and the learners put the lines in the correct order. Another listening activity which I have used in teacher training seminars has been to read a poem at normal speed and ask the participants to write down as much as they can. After about three hearings most people have been able to complete the poem. There are numerous activities that the teacher can prepare in order to provide a stimulating learning situation for the language learner but in the framework of literature. The teacher's enthusiasm towards the material will undoubtedly be communicated to the learners. Fortunately, there are more textbooks on the market which help the teacher to develop new ideas in this area. For example, the teacher can offer three versions of a poem and the learners have to decide which version is the poet's final choice. Maley and Duff (53) offer three versions of The Eagle by Lord Tennyson. My own experience has been that students do not agree with the final version, however, this conclusion causes some amusement and rounds off a stimulating discussion on the use of effective language. This paper has examined how the use of literary texts can be a positive learning experience in the language classroom and concludes that their use should not only be to illustrate particular linguistic aspects but should also arouse the emotions in some way, that is, to encourage a reader response. One might suggest that using literature should enhance the learning situation and form an integral part of the learning process as a whole and should be introduced if and when the teacher feels it appropriate with a given learner group. Certainly, there seems to be more reference to literary texts in language course books (Headway Advanced Unit 2). Indeed, there are authors who encourage adapting some ideas and activities for use across the whole range of levels (Collie and Slater 2) Some educators might say that the sooner leaners are introduced to literature in the target language, the better.

\section{Works Cited}

Brumfit, C. J. Language and Literature Teaching: from Practice to Principle. Oxford: Pergamon Press, 1985. 
Brumfit, C. J. and R. A. Carter. Literature and Language Teaching. Oxford: Oxford UP, 1986. Carroll, L. Alice's Adventures Underground. London: Dover Publications, 1965.

Carter, R. and M. N. Long. The Web of Words. Cambridge: Cambridge UP, 1987.

Collie, J. and Slater, S. Literature in the Language Classroom. Cambridge: Cambridge UP, 1987.

Enkvist, N. E., J. Spencer and M. Gregory. Linguistics and Style. Oxford: Oxford UP, 1964.

Hill, J. Using Literature in Language Teaching. London: Macmillan, 1986.

Maley, A. and A. Duff The Inward Ear. Cambridge: Cambridge UP, 1989.

Maley, A. and S. Moulding. Poem into Poem. Cambridge: Cambridge UP, 1985.

Moody, H. L. B. Approaches to the Study of Literature. ELT Documents 115. Oxford: Pergamon Press, 1983. 17-37.

Newbrook, N. Extracts. Surrey: Nelson, 1989.

Valdes, J. M. Culture Bound. Cambridge: Cambridge UP, 1986. 